\title{
O RENOVADO CONSERVADORISMO DA AGENDA PÓS-MODERNA
}

\author{
MARIA CÉLIA MARCONDES DE MORAES \\ Centro de Ciências da Educação da Universidade Federal de Santa Catarina - Florianópolis \\ mcmm@uol.com.br
}

\section{RESUMO}

Oartigo tem como objetivo discutir aspectos da agenda pós-moderna e a permanência de sua vitalidade nos dias de hoje. Seu ponto de partida são as idéias desenvolvidas pela autora em artigos anteriores, nos quais privilegia a crítica às principais propostas das tendências "pós": o relativismo epistemológico, a suspeita em relação ao conhecimento objetivo e ao caráter estruturado das coisas e do mundo. Na primeira parte, retomam-se os textos de 1996 e 1998, que apresentam, ainda que rapidamente, as origens da "agenda pós" e indicam alguns de seus desdobramentos, notadamente a virada lingüística e a supressão das fronteiras entre História e Literatura; na segunda, recuperam-se as idéias expostas nos textos de 1998 e 2003, com vistas a mostrar algumas características do pensamento neopragmático de Richard Rorty. Finalmente, assinalam-se as principais repercussões desta ampla agenda na pesquisa e em práticas educacionais.

PÓS-MODERNO-RORTY,RICHARD-EDUCAÇÃO

\section{ABSTRACT}

THE NEOCONSERVANTISM OF THE POST-MODERN AGENDA. The article aims to discuss some features of the postmodern agenda and the possible vitality of this trend of thought nowadays. The main framework of the article are the ideas presented in some of the author's previous essays (1996, 1997, 1998, 2003) where she sustains a critical position concerning the various "post" trends and emphasizes their epistemological relativism, their suspicion of the objective knowledge and their mistrust on the structured character of things and of the world. In the first part, the article recalls the ideas exposed in the works published in 1996 and 1998, and outlines the beginnings of the "post" agenda and of some of its developments, in particular the linguistic turn and the suppression of the boundaries between History and Literature; in the second part, it summarizes the analyses of Richard Rorty's neopragmatism, previously introduced in the texts of 1998 and 2003. Finally, the article indicates the impacts of this broad agenda on educational practices and on educational research. POST-MODERN - RORTY, RICHARD - EDUCATION

Agradeço as críticas e sugestões de Newton Duarte e Ricardo Gaspar Müller. 
A viagem não acaba nunca. Só os viajantes acabam. E mesmo estes podem prolongar-se em memória, em lembrança, em narrativa. Quando o visitante sentou na areia da praia e disse:

"Não há mais o que ver", saiba que não era assim. O fim de uma viagem é apenas o começo de outra. É preciso ver o que não foi visto, ver outra vez o que se viu já, ver na primavera o que se vira no verão, ver de dia o que se viu de noite, com o sol onde primeiramente a chuva caía, ver a seara verde, o fruto maduro, a pedra que mudou de lugar, a sombra que aqui não estava. É preciso voltar aos passos que foram dados, para repetir e para traçar caminhos novos ao lado deles. É preciso recomeçar a viagem. Sempre.

José Saramago

O Caderno Mais!, da Folha de S.Paulo, de 2 de novembro de 2003, publicou um interessante debate acerca da eventual morte do que se convencionou chamar de pós-moderno ou pós-modernismo. O mote foi o lançamento do último livro de Terry Eagleton (2003), After theory. A argumentação dos autores convidados dividiu-se entre as teses que propõem o pós-moderno como uma nova era nas artes, ciências e civilização e as que o afirmam como um blefe, um engodo já desmentido pela história. Se a polêmica em torno da existência ou não de uma "agenda pós-moderna" é tão antiga quanto os seus primeiros arautos - que se fizeram visíveis em meados do século $X X$, propagando suas idéias, sobretudo, nos anos de 1970 e 1980 -, ou seja, se a disputa não é de hoje, o debate ganhou novo impulso após os eventos de II de setembro. A data, que muitos consideram ser o marco de abertura do novo milênio, sinalizaria também o fim do que muitos consideraram um modismo, o pensamento pós-moderno. Para Eagleton (2003, p.22I) "com a nova narrativa global do capitalismo, juntamente com assim chamada guerra contra o terror, é bem possível que o estilo de pensamento conhecido como pós-modernismo esteja chegando ao fim".

Afinal, acrescenta o autor, foi esta corrente de pensamento que assegurou que as grandes narrativas eram coisa do passado. No entanto, testemunhamos hoje em dia a cruzada de Bush contra o "eixo do mal" que ressuscitou, até pelos termos religiosos em que é concebida, o que os pensadores pós-modernos consideravam definitivamente superado'. Diante desta nova realidade, o ceticis-

I Eagleton lembra que após aquela data alguns termos tornaram-se voga nos Estados Unidos, por exemplo, o "mal", os "amantes da liberdade", os "homens maus", "os patriotas", os 
mo e o relativismo pós-modernos têm agora que enfrentar verdades e termos inquestionáveis e totalizadores; sua concepção de micropoderes, em tempos de ultraliberalismo, desmancha-se ante o ressurgimento de um vigoroso Leviatã estatal (Soares, 2003); em oposição a seu entendimento da história como "sucessão de presentes perpétuos" (Jameson, 1988, p.26), anuncia-se, renovado, o velho e rejeitado jargão moderno do "progresso", da história linear e cumulativa. A nova realidade, enfim, teria desgastado as tendências de pensamento pós-moderno, levando-as à dissolução².

Essas questões têm levado intelectuais de diversas áreas a refletir sobre a validade ou não do conceito de pós-moderno nos dias de hoje. Constata-se, como se pode perceber pela leitura do Caderno Mais!, que a tese de uma exaustão do pensamento pós-moderno está longe de ser consensual. Ela sinaliza, porém, fortes mudanças no que se considerava, há pouco tempo, fato consumado, evidente e de contornos tão inquestionáveis quanto a globalização e o receituário econômico liberalizante do Consenso de Washington (Soares, 2003).

Com vistas a contribuir para o debate, retomo algumas idéias que elaborei nos últimos anos acerca desta temática, procurando ressituá-las no debate contemporâneo. Refiro-me aos artigos: "Os 'pós-ismos' e outras querelas ideológicas" ( 1996), no qual demarco o pós-moderno como uma "agenda", procuro acompanhar seu surgimento e analisar algumas das conseqüências de suas propostas para as Ciências Sociais, a História e a Educação; "História, estórias: morte do real ou derrota do pensamento", em co-autoria com Mário Duayer (1998), no qual discutimos o vácuo aberto pelo colapso do real - proposto pelos pós-modernos - e suas decorrentes irresoluções epistemológicas; e "Ceticismo epistemológico, ironia

"antiamericanos". A seu ver, essa terminologia não é necessariamente equivocada por indicar, por exemplo, que a liberdade é um valor a ser preservado. A questão é outra: a força desses termos é a de sugerir que, além deles, "nada mais há a ser dito". O postscript da edição norteamericana de After theory (New York: Perseus Books, 2003, do qual foi retirada esta citação, não foi acrescentado à edição britânica da Penguin Books, p.223).

2 Como afirma Eagleton, referindo-se a tempos anteriores aos que hoje presenciamos e antecipando a eventual dissolução do pós-moderno, "Julia Kristeva e o grupo Te/ Que/voltaram-se para o misticismo religioso e para a celebração do estilo de vida americano. O pluralismo pósestruturalista passa a ser agora mais bem exemplificado pelo supermercado norte-americano do que pela revolução cultural chinesa. Roland Barthes abandonou a política pelo prazer. Jean-François Lyotard voltou-se às viagens intergalácticas e apoiou o representante da direita, Giscard, nas eleições presidenciais francesas. Michel Foucault renunciou a qualquer aspiração de uma nova ordem social" (Eagleton, 2003, p.37). 
complacente: considerações acerca do neopragmatismo de Richard Rorty” (2003), no qual apresento as críticas de Rorty à filosofia ocidental, às concepções tradicionais de conhecimento e de verdade e o ceticismo epistemológico decorrente. $\mathrm{Na}$ discussão do pensamento rortyano, recorro também ao texto que publiquei com Mário Duayer (1997), "Neopragmatismo: a história como contingência absoluta".

Como qualquer pensamento, os que compõem a agenda pós-moderna, modismos ou não, transmutam-se no decorrer da história. Assim, se é difícil conceber a sobrevida de um pensamento pós-moderno tal como manifesto por seus primeiros representantes - que, de modo geral, asseveravam a derrota do projeto iluminista de emancipação, a mentira do progresso histórico, a fragilidade do sujeito, a impossibilidade da verdade, a negação do real, a recusa de fundamentos, rejeitavam as grandes narrativas, denunciavam a ciência e a racionalidade ocidental como imbricadas à estrutura de poder, à razão instrumental e à dominação -, é nítida a sobrevida de facetas da agenda pós-moderna como, por exemplo, suas vertentes culturalistas e neopragmáticas.

É este o contexto das idéias que exponho neste artigo. Sua exposição dividese em três partes. Na primeira, retomo as idéias expostas nos dois primeiros textos referidos e apresento, ainda que rapidamente, as origens da "agenda pós", indicando alguns de seus desdobramentos, notadamente a virada lingüística e a supressão das fronteiras entre História e Literatura; na segunda, apresento aspectos do pensamento neopragmático de Richard Rorty. Finalmente, assinalo o que, a meu ver, são as principais repercussões desta ampla agenda na pesquisa em educação.

\section{AS CONTROVÉRSIAS DA AGENDA PÓS-MODERNA}

Uma primeira observação é a de que a agenda pós-moderna e as teorias que a compõem jamais expressaram um corpo conceitual coerente e unificado. Divergem quanto à persuasão política, à perspectiva filosófica e à estrutura do raciocínio. Argumentos pós e neomodernos, pós-estruturalistas, pós-analíticos, pósmetafísicos, pós-marxistas, retóricos, pós-coloniais, hermenêuticos, culturalistas, os do fim-da-história, os neopragmáticos, entre outros, compuseram esta agenda e participaram da grande "conversação" filosófica que animou a intelligentsia nas últimas décadas do século XX. Vivia-se, então, um clima de "pós-condição", na feliz expressão de $\operatorname{Ahmad}($ 1996, p. I).

Não é de estranhar, portanto, que a pretensão de delimitar o sentido da agenda pós-moderna depare-se com uma pluralidade de propostas e interpretações, 
muitas vezes conflitantes entre si. Entre seus representantes mais notáveis - aliás, entre os representantes de qualquer uma de suas frações - existem diferenças marcantes e só uma leitura superficial poderia incluí-los na mesma corrente de pensamento. Na verdade, o que se convencionou chamar de pós-moderno adquiriu tamanha abrangência que se transformou em um "conceito guarda-chuva", um tipo de catch all category, mais propriamente uma "agenda", dizendo respeito a quase tudo: de questões estéticas e culturais a filosóficas, político-sociais e educacionais (Moraes, 1996).

O termo, no entanto, já nos anos de 1970, entrara definitivamente na linguagem cotidiana e tornara-se uma influente imagem cultural. Talvez porque tenha traduzido, no mais das vezes de forma confusa e imprecisa, as mudanças na vida social, política e moral impostas pelas múltiplas formas de reestruturação produtiva das últimas décadas do século passado. $\bigcirc$ debate promovido pelo Mais! pode ser visto como uma demonstração, ainda hoje, da influência da imagem cultural pós-moderna.

Vejamos, ainda que de modo aproximado, o horizonte de questões a que se refere o termo. $\bigcirc$ pós-moderno define-se melhor em sua contraposição às propostas do Esclarecimento, usualmente associadas ao "mundo moderno". O sufixo "pós", neste caso, indica uma inversão de sinais e símbolos, uma negação muitas vezes grosseira e caricata daquele momento da história e de suas práticas teóricas, políticas e culturais. Nessa inversão, a agenda

...coloca sob suspeita a confiança do Esclarecimento em uma razão capaz de elaborar normas, construir sistemas de pensamento e de ação e da habilidade racional de planejar de forma duradoura a ordem social e política. Questiona o sentido de uma racionalidade que se proclama fonte do progresso do saber e da sociedade, racionalidade vista como locus privilegiado da verdade e do conhecimento objetivo e sistemático. Critica a representação e a idéia de que a teoria espelha a realidade, bem como a linguagem como meio transparente para "idéias claras e distintas". Denuncia a falência do processo de modernização que, longe de cumprir suas promessas de progresso e emancipação, tornou-se força opressora sobre mulheres e homens, dominou a natureza, produziu sofrimento e miséria. Desconfia do humanismo, acusa a arrogância das grandes narrativas e sua pretensão a uma unidade onisciente. (Moraes, 1996, p.47)

Crítica pertinente, como se vê, mas de inegável caráter idealista: o complexo de forças históricas que determinam o desenvolvimento social é omitido e na ba- 
lança só figuram idéias difusas do Esclarecimento, sobretudo as de Kant e Condorcet. Este talvez seja o ponto mais frágil da agenda pós-moderna e seu mais evidente pomo de discórdia: considerar as complexas determinações das forças históricas uma metanarrativa e, ao desprezá-las, reduzir a história a uma narrativa sobre o único e o contingente.

Tais idéias refletiram-se, de imediato, no campo mais especificamente político. A ênfase na natureza fragmentada do mundo e do conhecimento humano trouxe como conseqüência a impossibilidade de qualquer política emancipatória em uma perspectiva totalizante, proposta tida como uma "metanarrativa iluminista", no mínimo ultrapassada. Teóricos pós-modernos expressavam suas reivindicações na linguagem da diferença e do particularismo, afirmavam serem ilusórias as formas institucionalizadas de poder, sobretudo os macropoderes (o do Estado, por exemplo), pois concebiam - na mais pura tradição foucaultiana - a realidade social como tecida por uma rede capilar de saberes e micropoderes que vigiam e disciplinam a vida privada, a social e a política. Nesse contexto, celebraram os interesses singulares de grupos políticos, enfatizaram a micropolítica, a identidade dos novos movimentos sociais, a multiplicidade das lutas fraturadas (Moraes, 1996). Nas palavras de Eagleton:

A emancipação que falhara nas ruas e nas fábricas pôde ser substituída pelas intensidades eróticas de um significante sempre a flutuar [...]. Novas teorias do discurso, do desvio e do desejo não eram simples alternativas a um discurso de esquerda que fracassara. Apresentavam-se, também, como formas de enriquecê-lo e aprofundálo. [...] A teoria cultural lá estava para fazer ver, à esquerda tradicional, aquilo que ela desprezara: arte, prazer, gênero, poder, sexualidade, linguagem, loucura, desejo, espiritualidade, a família, o corpo, o ecossistema, o inconsciente, as etnias, os estilos de vida, a hegemonia. (Eagleton, 2003, p.29-30)

Cativada pelos novos objetos, a agenda pós-moderna mostrava-se cética quanto às pesquisas voltadas aos estudos do trabalho, da classe ou das determinações econômicas da vida social e privilegiava as identidades que ocupavam os novos cenários. De acordo com Geary,

.... história deixa de ser um relato do passado e torna-se um terreno de disputa entre narrativas ou discursos, eles próprios construídos de forma autobiográfica. Comunidades são "imaginadas", e não criadas por uma realidade social independente da linguagem ou da cultura. [...] A diversidade é afirmada e não a unidade. As identidades são forjadas durante a ação, a partir do engajamento com discursos 
culturais e políticos; não existem realidades sociais prévias que possam dar origem às ações, à linguagem e cultura. (2000, p.39)

Se, por um lado, a agenda pós-moderna pôs a nu o descaso da esquerda com questões basilares da existência humana, por outro, e neste mesmo movimento, tornou descartáveis o conhecimento objetivo, a apreensão do real, a verdade, a racionalidade. Justo no momento em que as "corporações transnacionais se espalharam de um canto a outro do planeta, os intelectuais insistiam em bradar que a universalidade era uma ilusão" (Eagleton, 2003, p.50). Aliás, somos contemporâneos da direção e do sentido que a triunfante nova direita imprime ao rosto da Terra, e do recuo da esquerda ao pragmatismo e de seu questionamento da própria legitimidade da teoria.

As conseqüências não foram - e não são - triviais. Sobretudo quando se lembra que esse processo se fez acompanhar por uma relevante mutação no que se refere ao papel e à natureza da linguagem. A repercussão não tardou a se manifestar, notadamente na História, que, em larga medida, passou a ser mero registro aleatório da memória de personagens coadjuvantes. Nas palavras de Frederico, "a historiografia tornou-se uma espécie de reportagem ou crônica antropológica sobre o cotidiano indiferenciado construído a partir dos discursos daqueles personagens" (Frederico, 1997, p. 175).

Em lugar da linguagem como rede de significantes e de significados, signos e significações, instituíram-se os jogos de linguagem sem sujeito; a comunicação deveria ser feita por "elementos de narrativa", por uma série de textos em intersecção uns com os outros, nos quais se produziam novos textos, outros textos, indefinidamente, em um processo contínuo de cortes e reatamentos sempre em diferentes combinações (Moraes, 1996). Uma proposta aparentemente mais apropriada ao "novo tipo de sistema capitalista movido mais pelo consumo do que pela produção, mais pela imagem do que pela realidade, mais pela mídia do que pelos moinhos de algodão" (Eagleton, 2003, p.38).

Chamo a atenção para este importante viés da agenda "pós": a mudança de eixo, o "salto" da realidade para o texto como agente constitutivo da consciência humana e da produção social do sentido. Foi a sedução da assim chamada virada lingüística, então levada a extremos pela suposição de que há uma anterioridade da linguagem em relação ao mundo real e assim, o que se pode experimentar como "realidade" nada mais seria do que um constructo ou um "efeito" do sistema particular de linguagem ao qual pertencemos (Moraes, 1996). Bastaria, então, sublinhar os silêncios e as ausências na linguagem, desconstruir textos, desmascarar os modos 
pelos quais a linguagem esconde de si mesma sua inabilidade de representar algo para além de suas fronteiras. Nesta estratégia sem finalidade, a linguagem como que descolou da realidade, que reduzida a este jogo intertextual, não mais se distingue da ficção (Duayer, Moraes, 1998).

Nos textos de 1996 e 1998, assinalávamos os perturbadores efeitos da virada lingüística para o estudo da História e para a própria Literatura. A concepção de realidade como um constructo, ou um mero resultado de um sistema particular de linguagem, esfacelou a confiança na relação entre palavras e coisas, entre linguagem e realidade extralingüística. Firmou-se a proposição: conhecemos o que construímos. As conseqüências, a meu ver, foram dramáticas. A dissolução da efetividade do signo implicou, em última análise, a dissolução da própria História. A História - ou a Educação e a Literatura - como instâncias de expressão lingüísticas ou culturais, ficaram presas a esse universo. Só lhes restou expressar ou se referir a uma outra articulação de linguagem, a um outro consenso, a um outro discurso. Nada há para além do texto (Derrida), não existem territórios, apenas mapas (Baudrillard).

Mário Duayer e eu contestamos a obliteração dos limites entre História e Literatura. A nosso ver:

A Literatura possui um campo vastíssimo e, como se sabe, todo texto literário ocupa um determinado espaço social tanto como produto do mundo social dos autores quanto como agente textual atuando sobre este mundo, com o qual mantém uma relação complexa e contraditória. A Literatura, assim, ao mesmo tempo espelha e engendra o sentido de realidade de uma cultura e das formações sociais sobre as quais ela intervém para sustentar, resistir ou contestar, dependendo do caso em questão. Por este motivo, a Literatura, para além do que é em si mesma, será sempre uma inesgotável e rica fonte de informações para os historiadores. Entretanto, [...] o texto literário e o contexto histórico não são uma mesma trama: um não pode ser reduzido ao outro nem tomados como idênticos. A "narrativa" histórica constitui-se na possibilidade e no compromisso de compreender o contexto do qual a literatura faz parte, mesmo consciente de que não pode traduzi-lo mediante uma imagem categórica e definitiva. Sua meta é a de, pela análise do processo social real, expressar e problematizar a complexidade das determinações sociais do contexto histórico privilegiado, a estrutura interna que lhe é própria e que é continuamente renovada, recriada, redefinida. (Duayer, Moraes, 1998, p.70)

Os pregoeiros das teses que anulam as fronteiras entre ciência e ficção, entre História e Literatura, desordenaram os modos tradicionais de interpretação na 
Filosofia e nas Ciências Sociais e Humanas, colocando em xeque seus pontos básicos de sustentação e sua própria inteligibilidade. Colocou-se sob suspeita o conhecimento objetivo do mundo e, portanto, a possibilidade do agir humano sobre o mundo. Concordo com Norris que chegamos a um ponto no qual a teoria efetivamente se voltou contra si mesma, "gerando um tipo de ceticismo epistemológico extremo que reduz tudo - filosofia, política, criticismo e teoria - a um efeito retórico e persuasivo que encontra nos novos valores consensuais a última (e verdadeiramente única) instância legitimadora" (Norris, 1990, p.3-4). Nada mais regressivo, não obstante muitos considerarem que basta uma crítica mais consistente à metafísica e a desconstrução de seus textos para caracterizar uma atividade política radical. Aliás, foi o que sobrou de boa parte de agenda pós-moderna, o efeito retórico do gesto, o tom irônico da frase (Moraes, 1996).

Isto posto, chego à segunda parte da exposição. Tratarei de um dos rumos da agenda pós-moderna, a meu ver o mais vivo e penetrante de todos, a "virada pragmática". Privilegio o pragmatismo radical de Richard Rorty, o mais notável entre os representantes do neopragmatismo norte-americano. A opção deve-se não apenas ao fato de ele discorrer, sem rodeios, acerca da maioria das questões que são hoje candentes em todas as áreas, sejam teóricas ou práticas, mas, particularmente, porque expressa o espírito do tempo em que vivemos: as vogas pragmática, utilitarista, imediatista, perceptíveis em todos os setores, práticas e pensamentos que nos cercam.

\section{OUTRA FRONTEIRA SE ROMPE: A ENTRE CONHECER E MELHOR USAR AS COISAS}

Resumo, neste ponto, algumas considerações que desenvolvi no artigo "Ceticismo epistemológico, ironia complacente: considerações acerca do neopragmatismo de Richard Rorty" (2003), bem como as que apresentei, com Mário Duayer, em "Neopragmatismo: a história como contingência absoluta" ( 1997).

Pode-se dizer, grosso modo, que o procedimento de Rorty é traçado em dois eixos: por um lado, o de rever, a partir de uma metanarrativa pragmática, a tradição filosófica do Ocidente, "sucessão Platão-Kant", como ele a designa, com o propósito de "desmistificar" seus dualismos característicos como conhecimento/opinião, essência/acidente, realidade/aparência e a idéia de que uma investigação racional seria capaz de descobrir uma verdade oculta, uma "natureza intrínseca", por detrás ou mais além da realidade aparente. Rorty recusa, também, o corolário dessa 
proposta, o de que o conhecimento ou o acesso à verdade das coisas teria por pressuposto um movimento de distanciamento, racional e crítico, em relação a elas (Moraes, 2003). Por outro lado, e em perfeita consonância com o primeiro eixo, evoca e reconstrói o que a ele parecem ser a história edificante das instituições liberais norte-americanas e sua contínua vitalidade cultural.

A história de Rorty situa em passado longínquo o início da cristalização da filosofia ocidental que, reza sua narrativa, alcança rematada configuração na era moderna quando a filosofia deixou-se envolver pela "ansiedade cartesiana" ${ }^{3}$, obrigando-se a encontrar um ponto fixo a partir do qual estivessem asseguradas as condições do conhecimento e da verdade, sob pena de cair em total nillismo epistemológico (Moraes, 2003). A história relatada por Rorty situa aí o ponto de partida da dominância da metáfora da mente como "espelho da natureza", da verdade como adequação ou concordância, "e da filosofia como a disciplina cujo objetivo maior é o de examinar, polir e, acurada e detalhadamente, focalizar este espelho" (Duayer, Moraes, 1997, p.29).

Rorty conclama a revisão dessa história. Promete alcançar as metas que, a seu ver, foram estabelecidas por Wittgenstein, Heidegger e Dewey, os três "filósofos mais importantes de nosso século" - leia-se século XX -, os quais teriam situado a filosofia em um patamar distinto de suas formas anteriores, agora caídas em desuso. Tais metas seriam: a de livrar-se de vez da concepção kantiana de conhecimento; a de afastar a epistemologia e a metafísica como disciplinas possíveis; e, então, apresentar uma filosofia terapêutica e edificante em lugar da construtiva e sistemática (Rorty, 1994, p.21-23).

Em termos rortyanos, não haveria "nenhuma atividade chamada 'conhecimento' que tenha uma natureza a descobrir" (Rorty, 1997, p.32) e seria "o vocabulário da prática, e não o da teoria [...] o que pode revelar alguma coisa útil sobre a verdade" (Rorty, 1982, p. 162). É preciso, então, afirma Rorty, romper as fronteiras entre conhecer e usar as coisas, pois não se trata mais de obter um conhecimento objetivo da realidade, mas, tão somente, de indagar como utilizá-la melhor ${ }^{4}$. Por conseguinte, Rorty descarta a necessidade de indagar sobre a verdade, a objetividade ou sobre o que seria uma interpretação ou apreensão corretas da realidade. Em

3 Esta é uma interessante formulação de Bernstein (1998).

4 Qualquer semelhança com os princípios das pedagogias do "aprender a aprender" e das que privilegiam as "competências na escola", não será, por certo, mera coincidência (Duarte, 200 I, 2003; Ferreti, Silva Jr., Tartuce, 200 I). 
seu lugar propõe a aceitação das crenças úteis, as quais se explicam como reflexos de uma psicologia ao modo estímulo e resposta, e não por aspectos normativos assegurados pela epistemologia (Moraes, 2003).

No artigo sobre Rorty indico que, de seu ponto de vista, ser racional é habituarse a alcançar o consenso e, sob tal ótica, a racionalidade delineia-se na aprendizagem de técnicas de persuasão, tipos de justificação, formas de comunicação, de conversação e de prática social. A conversação substitui o confronto, a solidariedade se põe no lugar da objetividade (Moraes, 2003). Para Rorty, ser racional é estar de acordo com o que "nossa" cultura justifica como racional. Dito de outro modo, a racionalidade, a verdade e a linguagem têm suas origens na arbitrariedade e na contingência e nada mais seriam do que "ferramentas", recursos úteis disponíveis para lidarmos com "nossa" vida cotidiana. Enquanto tais são essencialmente relativas a finalidades e interesses também variáveis e contingentes, e são definidas pelo papel que desempenham no contexto do debate. São, portanto, necessariamente noções de uma cultura, sempre etnocêntricas (Duayer, Moraes, 1997, p. I 19). Nas palavras de Rorty, "nada há a se dizer sobre a verdade ou a racionalidade fora das descrições fornecidas por procedimentos familiares de justificação que uma dada sociedade - nossa - se utiliza" (Rorty, 1997, p.42). Verdade, conhecimento, racionalidade, assevera Rorty, são apenas elogios para as crenças socialmente justificadas.

Nessas circunstâncias, qualquer idéia de ciência como conhecimento objetivo do real é inteiramente descartada. Revelando sua filiação à agenda pósmoderna, o neopragmatismo vê a ciência como "um tipo de literatura", propõe a literatura e as artes como investigação, no mesmo patamar que a investigação científica. A ciência comporia apenas um dos setores da cultura - e nem mesmo o mais privilegiado ou interessante. É a literatura, deslocando a religião, a ciência e mesmo filosofia, que se transforma na disciplina dominante em nossa cultura (Rorty, 1982, p. 155). Em conseqüência, Rorty reconhece que se existem diferenças entre a física e a crítica literária, elas não são de ordem epistemológica, mas tão somente sociológica (Moraes, 2003).

O novo vocabulário introduzido por Rorty manifesta, entre outros aspectos, um aparente caráter anti-realista. Porém, ele próprio alerta para o fato de que seu anti-realismo não equivale a negar a existência da realidade. Assegurar a não existência de uma realidade independente da mente não significa, por exemplo, negar a existência de montanhas antes que tivéssemos, na mente, a idéia de montanha ou a palavra montanha na linguagem, nem, por outro lado, afirmar que as montanhas 
são um efeito do pensamento ou da linguagem (Moraes, 2003). O que os pragmáticos indagam, diz Rorty (2000), é se tem sentido "perguntar se a realidade é independente de nosso modo de falar sobre ela". Uma das verdades óbvias acerca das montanhas é a evidência de que existiam antes de começarmos a falar sobre elas. Quem não percebe esse fato, afirma Rorty, é pela simples razão de que "não sabe jogar os jogos de linguagem que utilizam a palavra 'montanha'. Mas a utilidade desses jogos de linguagem nada tem a ver com a pergunta se a realidade tal como é em si mesma, à margem da praticidade de sua descrição pelos seres humanos, contém montanhas" (2000, p. I00).

Assim é que para o neopragmatismo rortyano o mundo continua a existir, a conter os mesmos objetos, a causar os mesmos efeitos, não importa a descrição que dele fizermos ou as teorias que eventualmente possamos construir para explicá-lo. E prosseguiremos nossas vidas a aplicar descrições e a desenvolver teorias mesmo que, por definição, esteja excluída qualquer possibilidade de afirmar sua correspondência a "fatos". Teorias, dessa forma, serão sempre produtos deste ou daquele jogo de linguagem ou de uma prática científica socializada. Se a proposta rortyana não se aventura a negar a existência da realidade, refuta, porém, a possibilidade de a ela ter acesso fora do âmbito da cultura, da linguagem, dos interesses humanos. Ou seja, não obstante a afirmação da existência da realidade, o sistema de significações torna o acesso a ela impossível (Duayer, Moraes, 1997).

Elimina-se, então, qualquer possibilidade de um referente que transcenda as "marcas e ruídos" de que, insiste Rorty, consiste a cultura. Como Duayer e eu salientamos, ficam descartadas as questões sobre a objetividade do valor, a racionalidade da ciência e as causas da viabilidade de nossos jogos de linguagem. Adotar tal orientação significa substituir todas estas "questões teóricas" por "questões práticas" sobre a desejabilidade e/ou necessidade de "manter ou não nossos valores, teorias e práticas atuais" (Duayer, Moraes, 1997). As únicas restrições à pesquisa, segundo o autor, estão no campo da conversação e não na natureza do objeto, da mente ou da linguagem. Por essa razão, assevera Norris ( 1997, p.3), a persuasão (ou a retórica) seria o limite último da investigação.

No artigo assinalamos que as mesmas conclusões e implicações podem ser derivadas de uma análise da linguagem uma vez que, para Rorty, a linguagem é uma ferramenta ou conjunto de ferramentas que nos habilita a lidar com o mundo. Em tal interpretação, os vocabulários são instrumentos e não representações. Vejo a linguagem, afirma Rorty ( 199 |, p. |27), apenas como a forma pela qual os "seres humanos utilizam marcas e ruídos de uma cultura para alcançar o que desejam". 
Nesse sentido, "todo nosso conhecimento é conhecimento mediante descrições que resultam adequadas para nossos propósitos sociais correntes" (Rorty, 1997, p. 45). Nas palavras de Duayer e Moraes: "uma vez mais, o que importa é o fato de a linguagem permitir nosso transitar no mundo, isto é, nossa lida com o mundo e a cultura, a busca pela felicidade, a satisfação de nossas necessidades e desejos. Enfim, a linguagem afirma-se por sua utilidade, eficácia" (1997, p.38).

Interessante acompanhar a argumentação rortyana, como fizemos no artigo de 2003. Se alguém indaga "útil para quê?", nada há a replicar, assevera Rorty (1997), senão que são "úteis para criar um futuro melhor". Se as perguntas sucedem-se e alguém inquire "melhor segundo que critério?", os pragmáticos nada acrescentariam a não ser que "melhor" seria aquilo que "contém mais do que nós consideramos bom e menos do que consideramos mal". Se outros perguntam "exatamente o que consideram bom?", responder-se-ia "a variedade e a liberdade" ou o "crescimento". E como alcançar o crescimento, a variedade e a liberdade? Ora, mediante o intercâmbio de idéias, conversação, os encontros livres e abertos! $!^{5}$ Dessa forma, prossegue o autor, "os pragmáticos estão limitados a oferecer respostas imprecisas e inúteis porque não esperam que o futuro se ajuste a um plano [...], mas que tão somente assombre e estimule". Temos apenas que "perseguir as crenças que demonstrem ser guias confiáveis para obter o que queremos".

É evidente o ceticismo epistemológico do pensamento rortyano. Ceticismo que, em seu esforço de desnudar o conhecimento de qualquer vestígio de transcendência e na tentativa de naturalizá-lo e deflacioná-lo, acaba por trivializar a questão da verdade, tornando-a intrinsecamente descartável. Tais questões, por certo, escapam ao campo estrito da epistemologia. Tenho insistido, em outros trabalhos, que o debate sobre o ceticismo não se reduz, hoje em dia, a uma simples controvérsia sobre o conhecimento e os critérios de sua validação. Ao contrário, trata-se de uma discussão ideológica de largo espectro na qual se concentram e se enfrentam os vários protagonistas em presença na cena intelectual contemporânea, inclusive o neopragmatismo rortyano e sua proposição da verdade como consenso (Moraes, 2003). Consenso, não por acaso, coincidente com o modus operandidas "práticas e instituições das democracias liberais", pelo menos as "norte-atlânticas" (Duayer, Moraes, 1997, p.46).

5 Uma rede de internautas liderada por rortyanos tem como mote a frase, "este é não é um espaço para trocar idéias mas para trocar de idéias". 
Concluindo esta segunda parte, é preciso assinalar que a crítica à filosofia ocidental, à epistemologia, à noção de verdade e de representação, presentes em Rorty, não está desvinculada de sua teoria social - ou de sua utopia liberal - a meu ver, expressão e alimento do espírito da época. Quer-me parecer que Rorty encena um ceticismo radical, propõe-se crítico libertário de toda opressão (da verdade, da autoridade, dos universais etc.), mas pode ser igualmente lido como núncio de uma retórica que desabilita preventivamente qualquer crítica e práticas sociais que se contraponham aos "valores consensuais" das democracias liberais e que, nessa medida, serve de instrumento para a realização de seus próprios pressupostos. "Compreender, portanto, as propostas pragmáticas é relevante também no terreno das lutas sociais e políticas, sobretudo porque, neste âmbito, o que está em jogo é a pertinência ou não dos chamados ideais da modernidade, verdade, justiça, liberdade e emancipação" (idem).

\section{CETICISMO EPISTEMOLÓGICO E SUAS REPERCUSSÕES NA EDUCAÇÃO}

São de múltipla natureza as repercussões das propostas da agenda pósmoderna e, notadamente, do pragmatismo contemporâneo na educação. Menciono algumas delas.

Para Rorty, o objetivo da educação não é - nem poderia ser, considerando o exposto - a transferência de conhecimentos sobre questões epistemológicas ou a discussão sobre a verdade dos "fatos". Como assinalei, o neopragmatismo rortyano propõe substituir as "questões teóricas" por "questões práticas", sobre a desejabilidade e/ou necessidade de "manter ou não nossos valores, teorias e práticas atuais" ou, mais precisamente, por um processo permanente de ajuste aos vários interesses e necessidades culturais. Assim, não é de estranhar que ele afirme (1994, p.353-354) que "do ponto de vista educacional, campo oposto ao epistemológico ou tecnológico, o modo como as coisas são ditas é mais importante do que a posse de verdades". Além disso, porque considera o termo educação "um tanto prosaico demais" ele prefere um outro, "edificação", que, a seu ver, expressa melhor "esse projeto de encontrar modos novos, melhores, mais interessantes, mais fecundos de falar". Guiraldelli (1996) contrapõe o professor "ironista", defendido por Rorty, ao "ilustrado", supostamente defendido pela tradição moderna. Um possui o discurso sedutor da ironia complacente; o outro, o das verdades absolutas. Pergunto: seriam essas as únicas opções? 
Há que cuidar para não cair no falso dilema, ou na falácia, que a agenda pósmoderna nos propõe: metafísica ou relativismo; metanarrativas ou histórias fragmentárias, universalidade ou segmento, teoria totalitária ou nenhuma teoria; verdade como adequação ou verdade como consenso, neopragmatismo ou nenhum pensamento (Moraes, 1996, 2003). Esta falácia, em sua ironia destrutiva e regressiva, nivela toda a reivindicação ao conhecimento, a ponto de tudo parecer opções postas por diferentes interesses culturais.

No artigo de 1996 eu afirmava que os discursos da "pós-condição" - sobretudo na América Latina - têm efetivado uma inédita despolitização e cooptação da educação, apoiada nas críticas do fracasso de uma superada educação "humanista", de aporte "moderno" e "iluminista". Essas questões expressam a luta cultural travada pela nova direita que tranqüilamente incinera crenças e convicções no altar das mudanças planetárias na economia, na política, na tecnologia, na cultura (Moraes, 1996). No cotidiano, trata-se de postular o nexo direto entre educação e a recelebração das virtudes do mercado - afinal, é preciso preparar cidadãos para a economia do conhecimento -, do ocultamento da face fortemente excludente do consenso, das maneiras efetivas da dominação e da exclusão, dos modos pelos quais o passado se articula à lógica das formas históricas e culturais do presente (Moraes, 2003). Paralelamente, trata-se de desmoralizar a pertinência e a legitimidade da educação como uma questão pública e, até mesmo, pôr em dúvida a serventia da educação escolar, vista como símbolo das metanarrativas iluministas, dos "discursos universalizantes que subjugam e dominam", incapaz de dar conta dos "sujeitos mínimos" da pósmodernidade.

Mas, há outros desdobramentos da influência da agenda pós-moderna. Um dos aspectos que chamaram minha atenção nos últimos anos, seja como pesquisadora seja atuando junto à Coordenação de Aperfeiçoamento do Pessoal de Nível Superior - Capes -, é o movimento que denominei "recuo da teoria" na área de educação, mas também nas demais ciências humanas e sociais. Considero o ceticismo epistemológico da agenda pós-moderna e, sobretudo, o decorrente da visão pragmática da vida social, influências consideráveis sobre este movimento. Em outros trabalhos, já alertei para o fato de que a celebração do "fim da teoria" caminha pari passu com a promessa de uma utopia educacional alimentada por um indigesto pragmatismo que se evidencia nos critérios que têm norteado a elaboração das prioridades educativas nas políticas de formação, na elaboração de currículos, na organização escolar, em suma, em um projeto político que investe numa 
concepção empobrecida de pesquisa e na formação de um docente pouco adepto do exercício do pensamento (Moraes, 200 I).

$\mathrm{Na}$ esteira do ceticismo epistemológico e da lida pragmática em vigor, descarta-se a necessidade humana de inquirir sobre questões relativas à natureza do objeto e do próprio conhecimento. Estamos referindo-nos à tendência de plasmar o processo cognitivo no interior de limites que se definem pela eficácia, pela manipulação do tópico e do imediato. O prisma, agora, é bem mais sutil: o conhecimento é campo do "vocabulário da prática, e não da teoria”, como afirma Rorty. Assim, valoriza-se a ciência não pelo conhecimento que ela pode produzir, mas por seus subprodutos tecnológicos (informática, robótica, mídia, microeletrônica, telemedicina, teletrabalho, bibliotecas digitais, o ensino a distância). Estas inovações no campo do conhecimento, a meu ver, exercem impactos sensíveis na área educacional - embora seja cedo para perceber seus efeitos na pesquisa desenvolvida na área - uma vez que se faz fortemente presente nas definições de políticas públicas nacionais e nas emanadas pelas agências multilaterais.

Se o conhecimento é o vocabulário da prática e não o da teoria, não é de espantar o constructo de uma utopia praticista (Moraes, 200 I) que considera suficiente o "saber fazer" e o esforço teórico é associado à perda de tempo ou à especulação metafísica ou, quando não, restringe-se a um recurso de oratória, expediente persuasivo e fragmentário preso à sua própria estrutura discursiva. Dito de outro modo, trata-se de uma disposição que nivela o mundo reduzindo o cognoscível à experiência sensível. Tal disposição:

Avilta [...] as pesquisas educacionais por propô-las como simples levantamento de dados empíricos, como desenvolvimento de instrumentos de controle desses dados com vistas a descrever seu provável comportamento futuro, como estratégia de intervenção, ou ainda, em suas versões "pós", como narrativas fragmentadas, descrições vulgares das múltiplas faces do cotidiano escolar. (Moraes, Müller, 2003, p.330)

Nessas circunstâncias, a pesquisa educacional é tolhida em sua capacidade de apreensão das relações funcionais dos fenômenos empíricos e, se dilatarmos a questão de modo a nela incluir a experiência docente, a percebemos presa à negatividade intrínseca dos princípios das pedagogias do "aprender fazendo" ou do "aprender a aprender" (Duarte, 200 I). Concordo com Duarte (2003, p.620) que 
os tempos ditos pós-modernos caracterizam-se por "uma pedagogia que desvaloriza o conhecimento escolar e uma epistemologia que desvaloriza o conhecimento teórico/científico/acadêmico".

Seria extravagante negar a importância dos dados empíricos em qualquer pesquisa, pois é nos movimentos mais simples da vida quotidiana, na empiria mais imediata, que se situa o ponto de partida para compreender o ser social em seu sentido ontológico (Moraes, Muller, 2003). A meu ver, não há como ocultar o fato de que

...para além das marcas e ruídos de uma cultura, de que fala Rorty, para além da objetividade neopragmática definida no consenso, para além de "ser causado", há as relações tensas e complexas do que alguns de nós denominamos ontologia, a efetividade complexa do ser social, o real na essencialidade de relações concretas que instituem e constituem as relações econômicas, políticas e culturais no processo contraditório que é produto histórico do agir humano. Por isso mesmo, a complexidade do ser social é inteligível, por isso mesmo é efetividade real aberta ao conhecimento, à correta compreensão e à intervenção. (Moraes, 2003, p. 194)

Em decorrência, a teoria não deve abandonar o seu lugar catalisador na pesquisa e nem poderia ser de outra forma, assegura Duayer (2003, p.8), "já que em um mundo cada vez mais complexo teorizar é um imperativo da prática". O autor assinala que, não obstante a importância da empiria no contexto da pesquisa, ela não é suficiente para conferir inteligibilidade à experiência científica, uma vez que é preciso considerar o caráter estruturado dos objetos e do mundo. A conjunção constante de eventos no campo da empiria, por mais rica que seja, pressupõe o mundo fechado para mudanças e para a intervenção do agir humano. Porém, na medida em que as leis científicas só têm sentido se aplicadas em um mundo aberto (para além do âmbito da imediaticidade) e intransitivo, sua finalidade é a de compreender as estruturas, forças, poderes, que determinam os fenômenos empíricos, mas que se situam para além deles (Bhaskar, 1994).

Em contrapartida, e sob clara influência da agenda pós-moderna, se temas e objetos são hoje emergentes nas pesquisas educacionais, como gênero, etnias, geração, confissões religiosas, meio ambiente, multiculturalismo, imaginário, subjetividade, poder-saber, microrrelações, entre outros, devem ser pensados e discutidos com cuidado. Reduzidos à experiência imediata, à narrativa simbólica e descritiva, às histórias de vida coladas ao cotidiano - como infelizmente ocorre, em boa parte dos casos - reduzem-se a "microobjetos", fragmentos descolados, nômadas 
perdidas nas ilhas de discurso (Moraes, 200 I, 2003). Duarte lembra, a este respeito, a importância cada vez maior atribuída à chamada "troca de experiências em encontros da área educacional: em nome da valorização da experiência profissional de cada professor, o que acaba por existir é a legitimação do imediatismo, do pragmatismo e da superficialidade que caracterizam o cotidiano alienado" (Duarte, 200।, p.79).

Obviamente, não é o caso de resgatar a caricatura iluminista de racionalidade, verdade e conhecimentos que, diga-se de passagem, já foram denunciados há tempos, entre muitos outros e em perspectivas radicalmente diferentes, por Marx e Nietzsche ${ }^{6}$ e, neste século, por parte importante da tradição do marxismo ocidental. Não cabe esquecer, por certo, os malefícios que paradigmas absolutos trouxeram para a educação e para a pesquisa, de modo geral, ou a alienação de currículos inspirados pelo caráter estranhado e mistificador de certas "metanarrativas" . Há que se reconhecer que muitas das grandes sínteses do passado, ao aplainar as contradições do processo histórico, não só destruíram e renegaram as singularidades, mas com isso, renunciaram a qualquer possibilidade de um conhecimento efetivo sobre o real. Sabemos bem da cumplicidade tradicional da escola "moderna" com as estratégias excludentes do poder constituído, de sua contribuição para manter e aprofundar as clivagens existentes na sociedade, as divisões entre opressores e oprimidos - clivagens e divisões que, aliás, em nenhum tempo encontram sua origem na própria escola (Moraes, 1996).

Tais questões interessam de perto à educação. Nem tanto, talvez, à educação edificante e pragmática. Mas à educação como prática social privilegiada que, por ser assim, supõe sujeitos, não meros transmissores ou receptores de crenças

6 Vale lembrar, neste caso, o abismo que separa os dois autores. Marx, de modo geral, é renegado pelos pensadores pós-modernos - como não poderia deixar de ser, dada sua ênfase ao trabalho humano, ao estranhamento e às determinações econômicas da vida social. A crítica nietzscheana, ao contrário, constitui-se em uma das bases de inspiração deste pensamento.

7 É preciso cautela com a crítica às chamadas "grandes narrativas". Duayer refere-se ao autoengano do neopositivismo e das correntes relativistas da agenda "pós", "a saber, a noção de que o sujeito cognoscente cria o universal no pensamento. Idéia complementada, obviamente, pela ilusão simétrica de que o singular, porque é imediatamente dado à percepção, existe sem as determinações da universalidade e da particularidade e, por isso, pode ser apreendido automaticamente pelo aparato sensorial do sujeito. O que, é preciso adicionar, traz consigo ainda o absurdo pressuposto de que o sujeito percebe, classifica, pensa, enfim, sem as categorias do universal e do particular" (Duayer, 2003, p. I4, grifo meu). 
justificadas que lhes orientem as ações, mas educadores e educandos, na relação e no sentido mais profundos desses termos. Sujeitos que não desconhecem o importante papel de aculturação e adaptação que possui a educação, mas também o de resistência que lhe é tão próprio. Por reconhecerem assim a educação, não abdicam dos recursos da análise e da teoria seja para a crítica das práticas sociais existentes seja para sinalizar como é possível alterá-las, preservá-las, estendê-las, desafía-las. Sujeitos que admitem ser necessário compreender como interagem as práticas sociais e lingüísticas, os privilégios, as distinções, as distorções que elas abrigam. Sujeitos que entendem a resistência não como o simples choque entre diferentes crenças, mas como reconhecimento e apropriação do que existe de universal na cultura burguesa, para além das origens contextuais de seus produtos culturais. Em última análise, sujeitos que não ignoram que a transmissão do conhecimento e da verdade dos acontecimentos são instrumentos de luta - da sala de aula aos movimentos sociais (Moraes, 1996).

\section{REFERÊNCIAS BIBLIOGRÁFICAS}

AHMAD, A. A Teoria pós-colonial e a condição "pós". 1996. [Trabalho não publicado.]

BECK, C. Postmodernism, pedagogy, and philosophy of education. Urbana Illinois: Philosophy of Education Society, 1994.

BERNSTEIN, R. Beyond objectivism and relativism: science, hermeneutics, and praxis. Philadelphia: University of Pennsylvania Press, 1998.

BHASKAR, R. Plato etc.: the problems of philosophy and their resolution. New York: Verso, 1994.

DUARTE, N. Conhecimento tácito e conhecimento escolar na formação do professor (porque Donald Schön não entendeu Luria). Educação \& Sociedade, v. 24, n. 83, 2003.

Vigotski e o "aprender a aprender". 2. ed. Campinas: Editores Associados, 2001.

DUAYER, M. Economia depois do relativismo: crítica ontológica ou ceticismo instrumental? Niterói: UFF, Departamento de Economia, 2003. [Texto não publicado.]

Marx, verdade e discurso. Perspectiva, Florianópolis: NUP/CED/UFSC, v. 19, n. I, jan./jun. 2001 .

DUAYER, M. et al. Dilema da sociedade salarial: realismo ou ceticismo instrumental? Niterói: UFF/Departamento de Economia, 2000. [Texto não publicado] 
DUAYER, M.; MORAES, M. C. M. História, estórias: morte do real ou derrota do pensamento. Perspectiva, Florianópolis: NUP/CED/UFSC, v.16, n.29, jan./jul. 1998.

Neopragmatismo: a história como contingência absoluta. Tempo: Revista do Departamento de História da UFF, v. 2, n. 4, dez. 1997.

EAGLETON, T. After theory. London: Penguin; New York: Perseus, 2003.

FERRETI, C. J.; SILVA Jr., J. R.; TARTUCE, G. A Construção social da qualificação profissional. São Paulo: Fapesp, 200 I. [Relatório final de pesquisa.]

FREDERICO, C. A Lógica das coisas e a pós-modernidade. Revista Serviço Social e Sociedade, São Paulo: Cortez, n. 55, nov. 1997.

GEARY, D. A "Virada lingüística", pós-modernismo e história do trabalho. Perspectiva, Florianópolis: NUP/CED/UFSC, v. 18, n. 33, jan./jul. 2000.

GUIRALDELLI, P. A Filosofia contemporânea e a formação do professor: o "Aufklärung moderno" e o "liberal ironista". Perspectiva, Florianópolis, NUP/CED/ Editora da UFSC, v. I4, n.25, p.95-1 10, jan./jun. 1996.

JAMESON, F. The Syntax of history. London: Routledge, 1988. (v.2. The Ideologies of theory: essays, 197|-1986).

MORAES, M. C. M. Ceticismo epistemológico, ironia complacente: indagações acerca do neopragmatismo de Richard Rorty. In: MORAES, M. C. M. (org.) I/uminismo às avessas: produção de conhecimento e políticas de formação docente. Rio de Janeiro: DP\&A, 2003.

Os "Pós-ismos" e outras querelas ideológicas. Perspectiva, Florianópolis, NUP/CED; Editora da UFSC, v. 14, n. 25, jan./jun. 1996.

Recuo da teoria: dilemas da pesquisa em educação. Revista Portuguesa de Educação, v.|4, n. I, 2001.

MORAES, M. C. M.; MÜLLER, R. G. História e experiência: contribuições de E. P. Thompson à pesquisa em educação. Perspectiva, Florianópolis, NUP/CED/Editora da UFSC, v. 2 I , n.2, jul./dez. 2003.

NORRIS, C. What's wrong with postmodernism, critical theory and the end of philosophy. Hampstead: Harvester/Wheatsheaf, 1990.

. Treading water in Neurath's Ship, Quine, Davidson, Rorty. Principia: Revista Internacional de Epistemologia, Florianópolis, NEL/Editora da UFSC, v. 2, n. 2, dez. 1998. RORTY, R. Consequences of pragmatism. Hempstead: University of Minnesota Press, 1982. Contingency, irony and solidarity. Cambridge: Cambridge University Press, 1989. 
Education without dogma: truth, freedon, and our universities. Dissent, n.36, 1989a.

Essays on Heidegger and others. Cambridge: Cambridge University Press, 1991

A Filosofia e o espelho da natureza. Rio de Janeiro: Relume-Dumará, 1994. . Objectivity, relativism and truth. Cambridge: Cambridge University Press, 1991. Science as solidarity. In: NELSON, J. S.; MEGILL, A.; McCLOSKEY, D. M. (eds.) The Rethoric of the human sciences. Madison, WI: University of Wisconsin Press, 1997. Verdad y progreso, escritos filosóficos, 3. Buenos Aires, Barcelona, México: Paidós, 2000.

SOARES, C. C. Depois da teoria. Folha de S. Paulo, Caderno Mais! 2 nov. 2003.

Recebido em: abril 2004

Aprovado para publicação em: abril 2004 